\title{
Influence of Chemical Structure on Gas Separation Properties of Polymer Materials Based on Polyetherimide Ultem $₫$ and Silicon-Containing Copolyetherimide Siltem $\AA$
}

\author{
Yankova NA*, Yablokova MYu, Gasanova LG and Klyamkin SN \\ Chemistry Department, Lomonosov Moscow State University, Russia
}

Submission: November 01, 2017; Published: November 21, 2017

*Corresponding author: Yankova NA, Chemistry Department, Lomonosov Moscow State University, Russia, Email: yankovanatali@gmail.com

Abstract

Membrane materials based on polyimides possess high gas separation selectivity. Introduction silicon fragments in main chain of polymer can increase their productivity. Samples based on polyetherimide Ultem ${ }^{\circledR}$ and silicon-containing copolyetherimide Siltem ${ }^{\circledR}$ obtained using dry formation techniques. It was shown that changes in initial solution influence gas transport properties of the material.

\section{Introduction}

Gas separation by selective transport through polymeric membranes is one of the fastest growing branches of membrane technology. However, the existing polymeric membrane materials are inadequate to fully exploit the application opportunities on industrial scale; the improvement in permeability is the expense of selectivity, and vice versa.

\section{Materials and Methods}

The objects of the study were polyetherimide Ultem $\AA$ and copolyetherimide Siltem ${ }^{\circledR}$ (made by SABIC, Saudi Arabia) (Figure 1).

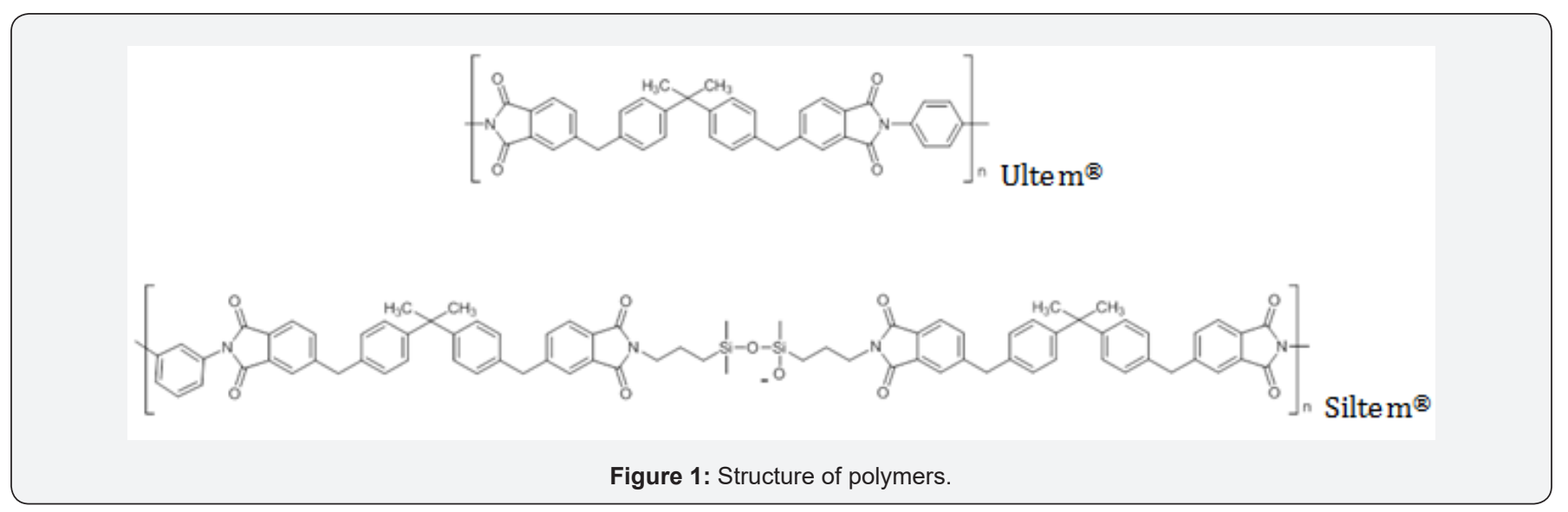

Gastransportcharacteristics (permeability and selectivity) were measured in the GKSS barometric apparatus (Germany) for samples Ultem $\AA 25 \%$ by weight (Ul25) and Siltem $\AA 25 \%$ by weight (S25) with NMP as solvent.
Results and Discussion

Materials selected for research

Polymers: The most interesting polymers for gas separation membranes are aromatic polyimides. They have 


\section{Recent Advances in Petrochemical Science}

a high selectivity for gas separation, thermal stability, good chemical and electrical insulation properties. The amorphous polyetherimide has $\mathrm{Tg} 150-250{ }^{\circ} \mathrm{C}$ that distinguishes them from other polyimides. Such polymers are interesting for study of the relationship «structure-properties». The introduction bulky substituents, polar groups, silicon-organic fragments leads to a significant change of formation conditions and density of nonporous membranes. The introduction of siliconorganic polymers fragments in structure leads to increased productivity of the membrane. It's expected that membranes based on of the new brand copolyetherimide Siltem ${ }^{\circledR}$ will be high selective as polyetherimide Ultem $₫$ and more permeable.

\section{Characteristics of the samples}

The density of the membrane depends on the intramolecular and intermolecular interactions in the basic polymer solution. Macromolecules in low concentration solution have a line shape and deploy from each other by a considerable distance. Macromolecules in high concentration solution have a sphere shape and deploy from each other by a little distance. Membranes will have a max density then line shape macromolecules deploy from each other by the little distance.

The introduction silicon-containing fragments leads to increasing density in general with same trend as for Ultem ${ }^{\circledR}$ and appearing max density for solution $25 \%$ wt. Increasing the Ultem ${ }^{\circledR}$ concentration also reduces the density of the composite samples, as base polymers, but less dramatically. We have very little researches of correlation between polymer concentration, gas separation properties and microstructure of the film samples. However, the effect of the concentration of the polymer solution shown by changing the rheological behavior. This behavior can lead to the formation of nonuniform structuring of polymers in thickness of the film samples.

Some contraction in a direction parallel to the surface that we can see could be due to lack of the polymeric body in the forming process and some macromolecule orientation during the evaporation of the solvent. Observed stratification may be associated with the appearing supersaturated solution of the polymer during heat removing of the solvent. Such heat treatment leads to forming structure with large number of bonds by intermolecular interactions and attraction-repulsion coordination of imide rings during convergence of the polymer chains in solvent removal process. The described features of the formation of the microstructure may have a significant impact on the transport characteristics of gas separation, particularly in polar gas permeability (Figure 2).

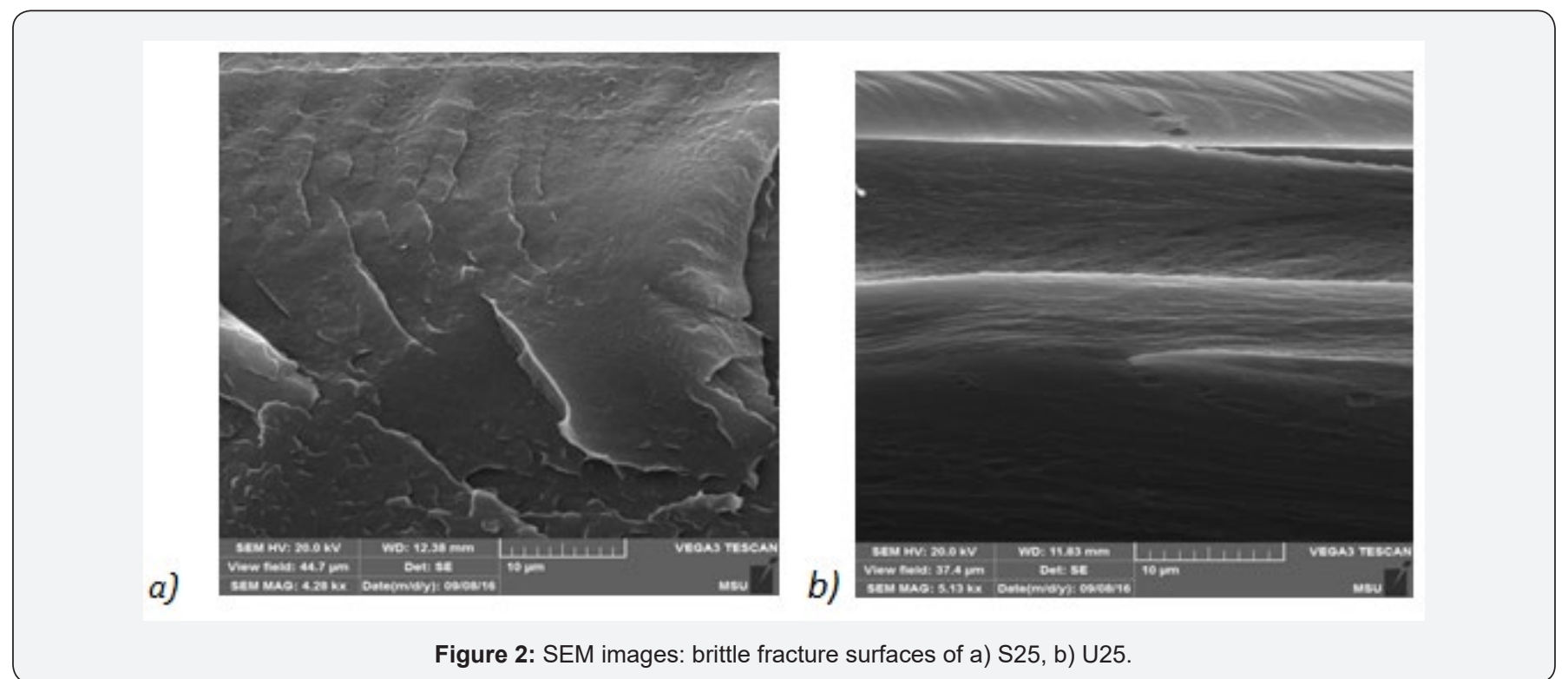

\section{Gas transport properties}

The introduction of silicon fragment increases the permeability for 5-15 times. Significantly influence the size of gas molecules significantly influence to growth of permeability, whereas the increasing of Ultem $\AA$ concentration to $30 \%$ results to increase of permeability for 8,5 times. For all samples Siltem ${ }^{\circledR}$ permeability of Heat level of the 02, Ar and $\mathrm{CH} 4$. As the Table 1 shows, the main changes of selectivity also are observed for film samples on the concentration of polymer in forming solution 23 to $25 \%$ by weight, and are mainly related to $\mathrm{H} 2$ and $\mathrm{CO} 2$ containing pare of gases. Further increasing of the polymer concentration of polymer in forming solution leads to constant selectivity for film samples. The level of the selectivity with increasing of concentration and decreasing of density at best remains constant (for Siltem ${ }^{\circledR}$ ) or reduced to loss of separation factor (for Ultem $\AA$ ) due to growth of permeability of all gases through "defective" polymer areas. (Table 1) 
Table 1: Transport parameters of the test membranes.

\begin{tabular}{|c|c|c|c|c|c|c|}
\hline & \multicolumn{2}{|c|}{$D^{1}$} & \multicolumn{2}{|c|}{$\mathbf{P}^{2}$} & \multicolumn{2}{|c|}{$\mathbf{S}^{3}$} \\
\hline & S25 & U25 & S25 & U25 & S25 & U25 \\
\hline $\mathrm{He}$ & 760 & 9 & 17 & 14 & 2 & 2 \\
\hline $\mathrm{H}_{2}$ & 370 & 24 & 19 & 16 & 5 & 7 \\
\hline $\mathrm{N}_{2}$ & 19 & 9 & 4 & 3 & 21 & 27 \\
\hline $\mathrm{O}_{2}$ & 24 & 9 & 8 & 6 & 35 & 23 \\
\hline $\mathrm{Ar}$ & 21 & 245 & 8 & 4 & 36 & 18 \\
\hline $\mathrm{CH}_{4}$ & 10 & 744 & 10 & 3 & 95 & 32 \\
\hline $\mathrm{CO}_{2}$ & 8 & 21 & 34 & 7 & 437 & 83 \\
\hline
\end{tabular}

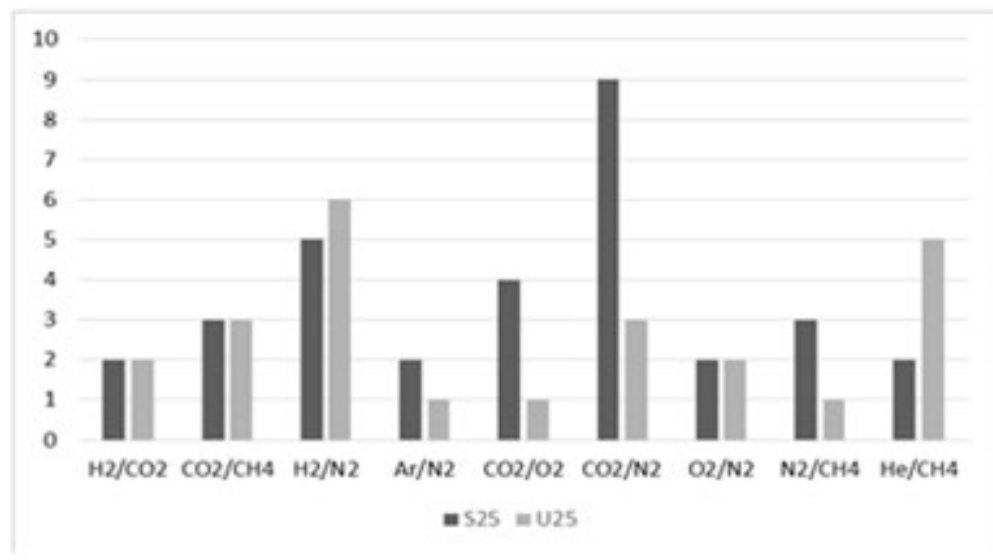

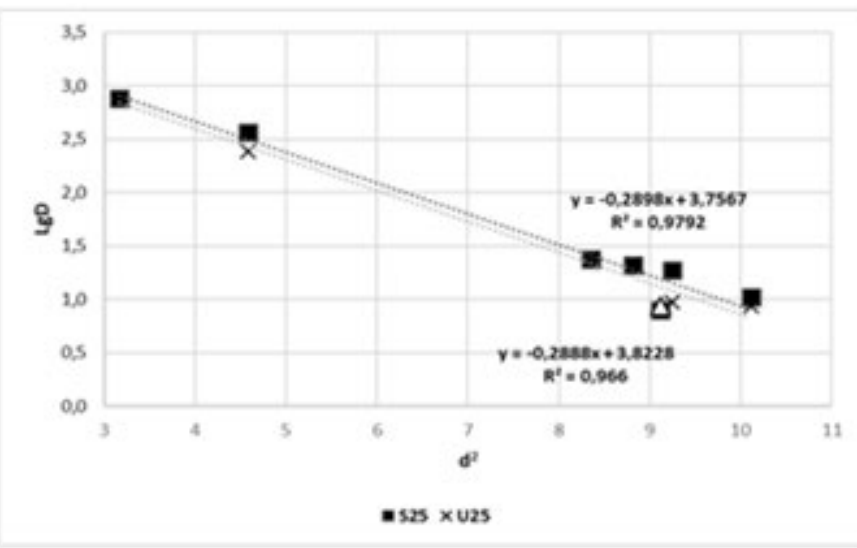

Since diffusion (D) and solubility coefficients (S) of various gases were determined, it is of interest to consider the classical correlations [ ], i.e., the correlations of $\operatorname{logS}$ with LennardJones potential energy parameter $\varepsilon / \mathrm{k}$ and the correlations of $\log \mathrm{D}$ with squared effective gas-kinetic diameter of diffusion molecules $\mathrm{d} 2$. In the case of the passive transport of gases in a polymer matrix, these correlations are linear; deviations of these correlations can indicate the occurrence of specific interactions.

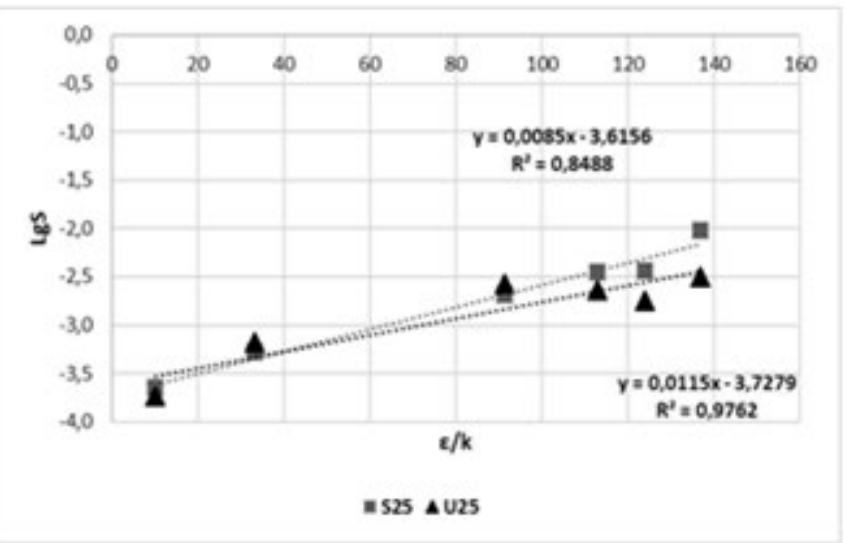

The film nonporous membranes based on new copolyetherimide Siltem ${ }^{\circledR}$ were prepared. It was shown that the introduction of silicon-organic polymers fragments in structure leads to increasing productivity of the membranes.

\section{References}

1. Teplyakov VV (1987) Zh. Vses. Khim. O-va 22: 693. 
This work is licensed under Creative Commons Attribution 4.0 Licens

DOI: 10.19080/RAPSCI.2017.03.555622

\section{Your next submission with Juniper Publishers will reach you the below assets}

- Quality Editorial service

- Swift Peer Review

- Reprints availability

- E-prints Service

- Manuscript Podcast for convenient understanding

- Global attainment for your research

- Manuscript accessibility in different formats

( Pdf, E-pub, Full Text, Audio)

- Unceasing customer service

Track the below URL for one-step submission https://juniperpublishers.com/online-submission.php 